\title{
Comparison of Enzymatic Recycling Electrodes for Measuring Aminophenol: Development of a Highly Sensitive Natriuretic Peptide Assay System
}

\author{
Yasuhiro Mie, ${ }^{* \dagger}$ Keiko Kowata, $*$ Yu Hirano, ${ }^{*}$ Osamu Niwa, ** and Fumio Mizutani* \\ *Hokkaido Center, National Institute of Advanced Industrial Science and Technology (AIST), \\ 2-17-2-1 Tsukisamu-higashi, Sapporo 062-8517, Japan \\ **Tsukuba Center, National Institute of Advanced Industrial Science and Technology (AIST), \\ 1-1-1 Higashi, Tsukuba 305-8566, Japan
}

\begin{abstract}
Several redox enzymes were examined for enzymatic/electrochemical-recycling systems in order to measure $p$-aminophenol (PAP) with high sensitivity. Glucose oxidase (GOD) and diaphorase (DI) worked well as catalysts for recycling electrode systems: these enzymes effectively reduced $p$-iminoquinone (PIQ), the electrochemically-oxidized form of PAP, and caused an enhancement in the electrochemical signals (anodic currents in the voltammogram and amperogram) by $\sim 100$ fold. The lower detection limits for PAP were estimated to be $50 \mathrm{nM}$ with the GOD system and $2 \mathrm{nM}$ with the DI system. We combined the enzymatic-recycling electrode using DI with an enzyme immunoassay system to measure atrial natriuretic peptide (ANP), an important marker peptide hormone involved in heart diseases. ANPs from serum samples at ppt-levels were determined appropriately using the present assay system.
\end{abstract}

(Received October 23, 2007; Accepted March 3, 2008; Published May 10, 2008)

\section{Introduction}

A-type (atrial) and B-type (brain) natriuretic peptides (ANP, $\mathrm{BNP})$ are synthesized in the heart; they have many pathophysiological roles, including natriuretic action and vasodilating action. ${ }^{1-3}$ Since the plasma levels of ANP and BNP increase in accordance with the severity of heart failure, measuring these peptides is very useful in both the diagnosis and the treatment of heart failure..$^{4-10}$ The concentrations of ANP and BNP in our blood under normal conditions are extremely low $\left(<40 \mathrm{pg} \mathrm{mL}^{-1}(\mathrm{ppt})\right)$, but rise to by $10-100$ fold in patients with severe congestive heart failure. ${ }^{11,12}$

To measure such low concentrations of peptides, recearchers have developed and commercialized highly-sensitive radioimmunoassays or enzyme immunoassays based on chemiluminescence or fluorescence. ${ }^{13-16}$ However, simple and inexpensive bedside measurements in ambulances, hospitals, and homes are difficult to accomplish with these methods, because the aforementioned methods require expensive and massive apparatuses. Therefore, the development of a simpler and cheaper assay system is necessary.

Since the electrochemical sensing system is very simple, timesaving, cost-effective, and easy to make portable, it may be useful to combine it with a highly-selective enzyme immunoassay system for the on-site measurement of

$\dagger$ To whom correspondence should be addressed.

E-mail: yasuhiro.mie@aist.go.jp

F. M. present address: Graduate School of Material Science, University of Hyogo, 3-2-1 Kouto, Kamigori, Ako-gun, Hyogo 678-1297, Japan. biomolecules. However, normal electrochemical detection techniques are less sensitive as compared with the aforementioned methods, and cannot measure ppt-levels of biomarkers. We have recently developed a highly sensitive surface electrochemical enzyme immunoassay technique ${ }^{17}$ that uses acetylcholinesterase (AChE) as a labeling enzyme. The enzyme reaction product, thiocholine, accumulated on the metal electrode surface by chemisorption through S-metal bonds, and the amount of accumulated molecules (which correlates with the enzyme activity) was estimated by the electrochemical reduction of the S-metal bonds. The accumulation step leads to the high sensitivity of the electrochemical enzyme immunoassay, and sub-ppt levels of BNP could be assayed. Although a highlysensitive electrochemical immunoassay was achieved, the electrochemical reduction step in the system needs a deaerated alkaline solution to obtain precise and reproducible results, and this might not be practical for clinical use.

In the present study, to develop a highly-sensitive assay system for ANP using an electrochemical detection method in neutral solution, we adopted the enzymatic recycling electrode system. In enzymatic recycling, an electrochemically active small molecule is used as a redox mediator, and the electrochemically oxidized (or reduced) mediator is then reduced (or oxidized) back by the redox enzyme(s), which leads to the redox cycling of the mediator to amplify the electrical current. ${ }^{18-20}$ Quinone derivatives such as $p$-aminophenol (PAP) are the most frequently studied mediators. We compared the abilities of several redox enzymes to function in an enzymatic recycling electrode system for PAP, and coupled the recycling system to an enzyme immunoassay to measure ANP. We thus achieved the ppt-level detection of ANP. 


\section{Experimental}

\section{Reagents and chemicals}

Glucose oxidase (GOD, EC 1.1.3.4, from Aspergillus sp.) and glucose dehydrogenase (NAD-dependent, EC 1.1.1.47, from microorganisms) were obtained from Toyobo Enzymes (Kyoto). Tyrosinase (EC 1.14.18.1, from mushroom) and laccase (EC 1.10.3.2, from Rhus vernificera) were purchased from Sigma Chemical (St. Louis). Diaphorase (DI, EC 1.6.99.-, from Bacillus stearothermophilus) was obtained from Unitika (Osaka). p-Aminophenyl phosphate (PAPP), the substrate of alkaline phosphatase, was obtained by the reduction of p-nitrophenyl phosphate (Wako Pure Chemical Ltd., Osaka) according to a previously-reported method. ${ }^{21}$ ANP (ANP-28, Human) and anti-ANP antibodies (rabbit anti-ANP-28 IgG) were obtained from Phoenix Pharmaceuticals (Belmont, CA).

\section{Apparatus}

Voltammetry and amperometry were performed with an electrochemical analyzer 400A (Bioanalytical Systems, West Lafyette, IN). A gold disk (diameter, $3 \mathrm{~mm}$; Bioanalytical Systems), an $\mathrm{Ag} / \mathrm{AgCl}$ electrode and a platinum wire were employed as the working, reference, and auxiliary electrodes, respectively. All potentials are reported in reference to a SHE (standard hydrogen electrode) at room temperature. The ÄKTAdesign chromatography system (Amersham Biosciences, Piscataway, NJ) was used for the purification of the enzyme conjugated anti-ANP antibody.

Preparation of enzyme-labeled anti-ANP IgG and ANP immobilized substrate

Alkaline phosphatase (ALP) conjugated anti-ANP antibodies (ALP-Ab) were prepared using an ALP labeling kit (Dojindo Co., Tokyo). The material was purified by gel filtration column chromatography with a Sephacryl S-300 HR column (Amersham Biosciences). An ANP-modified (gold) substrate for the separation of bound and free forms of ALP-Ab (Fig. 1) was prepared as previously described. ${ }^{17,22}$ A clean gold surface was modified with 8-amino-1-octanethiol (Dojindo Co.), and then ANP was covalently immobilized onto the $\mathrm{NH}_{2}$-terminated surface. The amount of ANP immobilized on the surface was estimated to be $c a$. $6.5 \times 10^{-11} \mathrm{~mol} \mathrm{\textrm {cm } ^ { - 2 }}$ by quartz crystal microbalance measurements, suggesting that there was a monolayer coverage.

\section{Electrochemical enzyme immunoassay procedure}

ANP was measured according to the scheme shown in Fig. 1. An aliquot of ANP was added to a buffer solution ( $\mathrm{pH} 7.4$ ) containing ALP-Ab (180 ng mL $\left.{ }^{-1}\right)$, and the mixture was stirred for $30 \mathrm{~min}$ to promote the immunochemical reactions. The ANP-modified substrate was inserted into the solution, and the mixture was stirred for $30 \mathrm{~min}$ so that any unreacted ALP-Ab would attach onto the electrode surface. The buffer solution contained $0.5 \%$ of $n$-dodecyl- $\beta$-D-maltoside (DDM; Dojindo Co.) to prevent the non-specific adsorption of ALP-Ab. DDM is reported to be useful for minimizing nonspecific protein adsorption. ${ }^{23}$ Although complete blocking of the non-specific binding of the antibody could not be achieved under the present conditions, a sufficient blocking effect was observed (the current due to nonspecific adsorption decreased to $5 \%$ ) to obtain stable responses in the present electrochemical immunoassay (a background current due to the non-specific binding of antibody was subtracted). The substrate with bound ALP-Ab was soaked in a $3 \mathrm{mM}$ PAPP solution for $15 \mathrm{~min}$ to form PAP. Finally, the



Fig. 1 Schematic representation of the procedure used to measure ANP electrochemically.

bioelectrocatalytic detection of the PAP was carried out amperometrically using the enzymatic recycling electrode system at $0.45 \mathrm{~V}$ vs. SHE. When GOD was used as the recycling enzyme, Ar gas was passed through the sample solution for $5 \mathrm{~min}$ before each electrochemical measurement.

\section{Results and Discussion}

\section{Enzymatic recycling electrodes for PAP}

Figure 2 shows the cyclic voltammograms obtained in a $10-\mu \mathrm{M}$ PAP solution in phosphate buffer ( $\mathrm{pH}$ 7.5) using a bare glassy carbon electrode in the absence and presence of the enzymatic recycling system. In the absence of the recycling system, a pair of reversible peaks corresponding to the oxidation of PAP (to $p$-iminoquinone (PIQ)) and the reduction of PIQ back to PAP were observed with a formal redox potential of $0.3 \mathrm{~V} v s$. SHE, as shown in Figs. $2 \mathrm{a}$ and $2 \mathrm{~b}$ with dotted lines. This is identical to a previously reported value. ${ }^{24}$ Upon the addition of GOD $\left(50 \mathrm{U} \mathrm{mL}^{-1}\right.$ $($ ca. $2 \mu \mathrm{M}))$ and glucose $(10 \mathrm{mM})$ to the PAP solution, the shape of the voltammogram changed to a catalytic sigmoidal curve, as shown in Fig. 2a(2). The oxidation (anodic) current of PAP was enhanced as the reduction (cathodic) current disappeared, which can be ascribed to the electrochemical oxidation of PAP (to PIQ) coupled with the GOD-catalyzed reduction of PIQ (to PAP). The overall reaction is a GOD-based bioelectrocatalytic oxidation of glucose with the PAP/PIQ redox couple as the mediators. The catalytic current was linear with the concentration of PAP up to at least $400 \mu \mathrm{M}$ (Fig. 3a). A detection limit of 50 $\mathrm{nM}$ was estimated under the present amperometric condition (at $0.45 \mathrm{~V}$ ). The consumption/regeneration cycle resulted in a highly sensitive assay for measuring PAP.

A similar result was obtained when DI was used in the enzymatic system instead of GOD. Upon the addition of DI (50 $\left.\mathrm{U} \mathrm{mL}^{-1}(c a .1 \mu \mathrm{M})\right)$ and NADPH $(5 \mathrm{mM})$ to the PAP solution, a greatly enhanced electrochemical response with a sigmoidal shape in the voltammogram was observed, as shown in Fig. 2a(3). In the DI case, the degree of enhancement of the amplified electrochemical signal (anodic current in the voltammogram) was about one order of magnitude greater than the GOD system, indicating that DI reduces PIQ (produced by the electrochemical oxidation of PAP) more efficiently in the present system. The catalytic current was linear with the concentration of PAP up to approximately $3 \mu \mathrm{M}$ (Fig. 3b). The lower detection limit was estimated to be $4 \mathrm{nM}$ under the present amperometric condition (at $0.45 \mathrm{~V}$ ). 

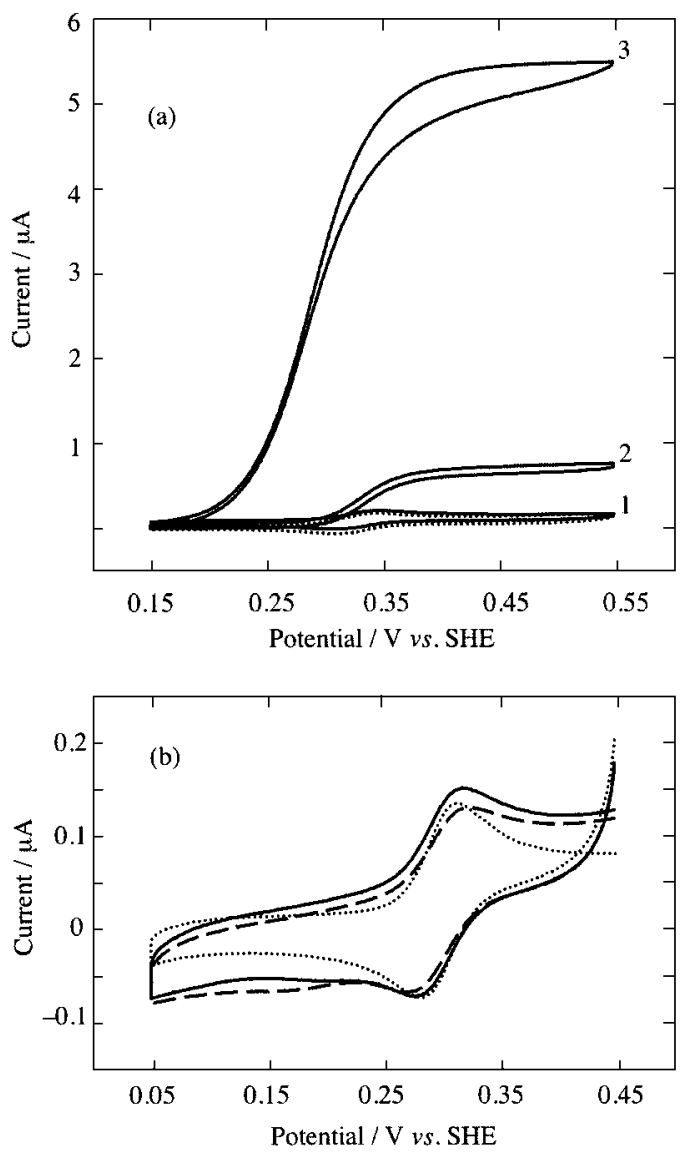

Fig. 2 Cyclic voltammograms of $10 \mu \mathrm{M}$ PAP in a phosphate buffer solution $(\mathrm{pH} 7.5)$ at a glassy carbon electrode in the absence and presence of an enzymatic-recycling system at a scan rate of $5 \mathrm{mV} \mathrm{s}^{-1}$. (a) Dotted line, PAP alone (in the absence of an enzymatic system); 1, $+50000 \mathrm{U} \mathrm{L} \mathrm{L}^{-1}$ glucose dehydrogenase and $10 \mathrm{mM}$ glucose; $2,+50000$ $\mathrm{U} \mathrm{L}^{-1}$ GOD and $10 \mathrm{mM}$ glucose; $3,+50000 \mathrm{U} \mathrm{L}^{-1}$ DI and $5 \mathrm{mM}$ NADPH. (b) Dotted line, PAP alone; dashed line, $+50000 \mathrm{U} \mathrm{L}^{-1}$ tyrosinase; solid line, $+50000 \mathrm{U} \mathrm{L}^{-1}$ laccase.

According to the theory of homogeneous mediated bioelectrocatalysis in quiet solutions, ${ }^{25}$ the bimolecular reaction rate constants between the enzymes and PIQ $\left(k_{\mathrm{cat}} / K_{\mathrm{m}}\right)$ can be estimated using a linear relationship between the obtained currents and the concentrations of the mediator. The reaction rates were $5.3 \times 10^{6} \mathrm{M}^{-1} \mathrm{~s}^{-1}$ between GOD and PIQ, and $5.6 \times 10^{8} \mathrm{M}^{-1} \mathrm{~s}^{-1}$ between DI and PIQ. The $5.6 \times 10^{8} \mathrm{M}^{-1} \mathrm{~s}^{-1}$ value between DI and PIQ is in good agreement with a previously-reported value. ${ }^{26}$ A two-orders-of-magnitude larger rate constant was obtained for DI-PIQ as compared to that for GOD-PIQ. Since the formal potentials $\left(E^{0 \prime}\right)$ of DI and GOD are reported as $-0.325 \mathrm{~V}^{26}$ and $-0.063 \mathrm{~V},{ }^{27}$ respectively, the $E^{0 \prime}$ value of PAP/PIQ $\left(E^{0^{\prime}}=0.3 \mathrm{~V}\right)$ is sufficiently more positive than those of these enzymes. The aforementioned facts indicate that the reactions between the enzymes and PIQ are diffusioncontrolled. ${ }^{25,26}$ One of the main reasons for the difference in the rate constants between DI-PIQ and GOD-PIQ could be due to the difference in the diffusion capability of these enzymes: GOD is a large homodimer with a molecular weight of $\sim 186 \mathrm{kDa}$, whereas DI is a medium-sized protein with a molecular weight of $24 \mathrm{kDa}$. The difference in the degree of interaction between the enzymes and PIQ may be sufficient to explain the present observation.

On the other hand, glucose dehydrogenase, tyrosinase, and
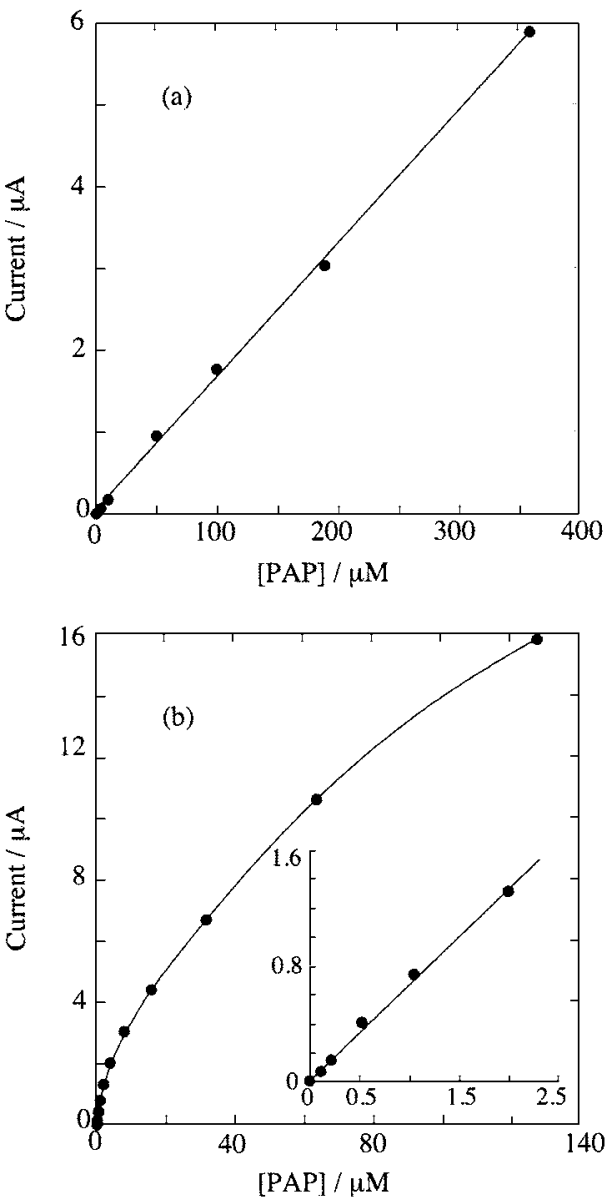

Fig. 3 Relationship between the electrode current observed in voltammograms of PAP at $0.45 \mathrm{~V}$ and the concentration of PAP in buffer solutions containing (a) GOD and (b) DI systems. (a) $50000 \mathrm{U}$ $\mathrm{L}^{-1}$ GOD, $10 \mathrm{mM}$ glucose. (b) $50000 \mathrm{U} \mathrm{L}^{-1} \mathrm{DI}, 5 \mathrm{mM}$ NADPH.

laccase were found to be less effective in amplifying the electrochemical signal of PAP, as shown in Figs. 2a(1) (glucose dehydrogenase) and $2 \mathrm{~b}$ (tyrosinase and laccase). Although we had expected increases in an anodic current with glucose dehydrogenase and in a cathodic current with tyrosinase or laccase, no remarkable enhancement in the electrical currents was observed with these enzymes. This suggests that a rapid electron transfer between these enzymes and PAP or PIQ did not occur. Since glucose dehydrogenase (the NAD-dependent type was used in this study) is known to have high substrate specificity, this could be the main reason for the slow electron transfer reaction. A well-amplified tyrosinase based bioelectrocatalysis using phenol has been previously reported, ${ }^{28}$ and we reproduced their results in the present study. However, when PAP was used instead of phenol, little amplified signal was obtained, as reported above, suggesting that tyrosinase does not specifically interact with aminophenol.

\section{Effect of enzyme immobilization}

Since GOD and DI were found to be highly effective in amplifying the electrochemical signal of PAP, we examined the immobilization of these enzymes onto an electrode surface, expecting further improvements in sensitivity. A highly-stable immobilization of GOD onto a glassy carbon electrode surface was achieved with the lipid modification method. ${ }^{29}$ With the GOD-modified electrode, a GOD-based bioelectrocatalytic 
Table 1 Comparison of enzymatic recycling systems for PAP detection in Figs. 3 and 4

\begin{tabular}{lccc}
\hline \multicolumn{1}{c}{ Enzyme } & $\begin{array}{c}\text { Linear range/ } \\
\mu \mathrm{M}\end{array}$ & $\begin{array}{c}\text { Equation of linear } \\
\text { regression }{ }^{\mathrm{a}}\left(r^{2}\right)\end{array}$ & $\begin{array}{c}\text { Detection limit/ } \\
\mathrm{nM}(S / N=3)\end{array}$ \\
\hline GOD in solution & $0.2-400$ & $I=0.06 C+0.04(0.9988)$ & 50 \\
GOD immobilized & $0.01-50$ & $I=0.046 C+0.003(0.9979)$ & 2 \\
DI in solution & $0.02-3$ & $I=0.68 C+0.02(0.9969)$ & 4 \\
DI immobilized & $0.004-2$ & $I=0.011 C+0.005(0.9969)$ & 1 \\
\hline
\end{tabular}

a. $I$ is the current $(\mu \mathrm{A})$ and $C$ is the concentration of PAP ( $\mu \mathrm{M}$ for in-solution cases, $\mathrm{nM}$ for immobilized cases).
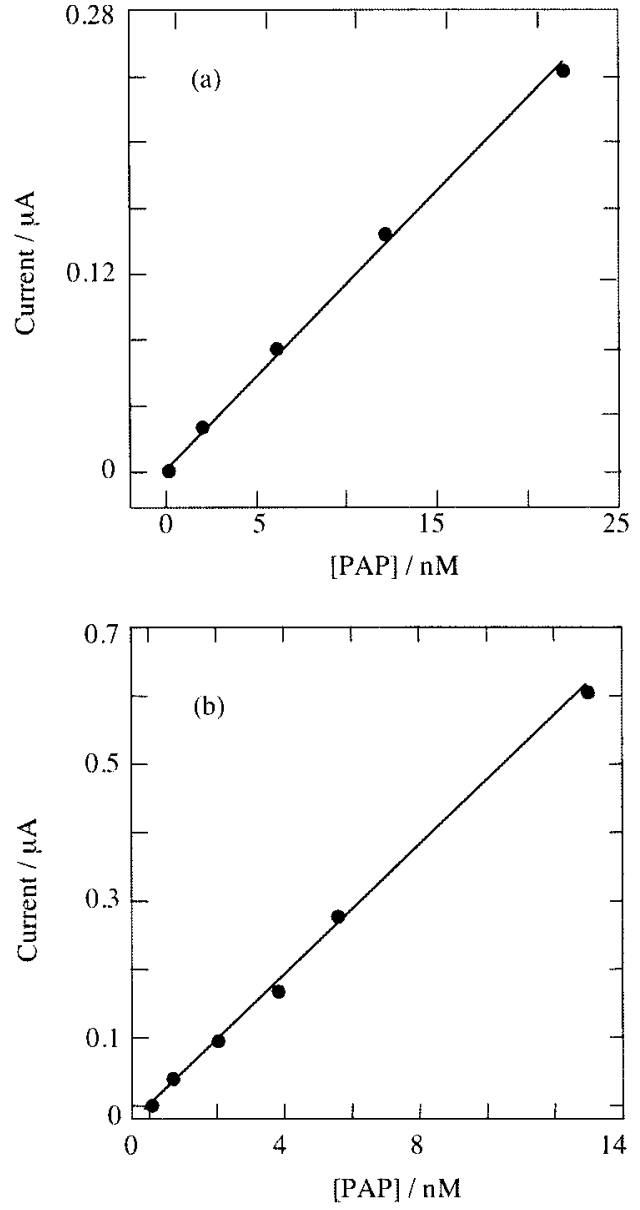

Fig. 4 Relationship between the voltammetric currents of PAP at $0.45 \mathrm{~V}$ observed at (a) GOD- and (b) DI-immobilized electrodes and the concentration of PAP in the buffer solutions.

voltammogram of PAP was observed, similar to the case of GOD in solution as shown in Fig. 2a. Note that the amplification magnitude of the anodic current of PAP in the GOD-immobilized electrode system was much greater than the anodic current of GOD in solution. When GOD was immobilized, an amplification of more than 100-fold for the anodic current of PAP was observed, whereas the GOD in solution system was about 8 -fold greater at its maximum. The detection limit was lowered to $2 \mathrm{nM}(S / N=3)$ from $50 \mathrm{nM}$ by immobilizing the enzyme (Fig. 4a). Table 1 compares the enzymatic recycling features for PAP detection in which the enzymes were either in solution or immobilized on the electrode surface. The GOD-immobilized electrode prepared in this study was highly stable: the electrochemical responses to PAP did not change for at least 6 months with $4^{\circ} \mathrm{C}$ storage after each use

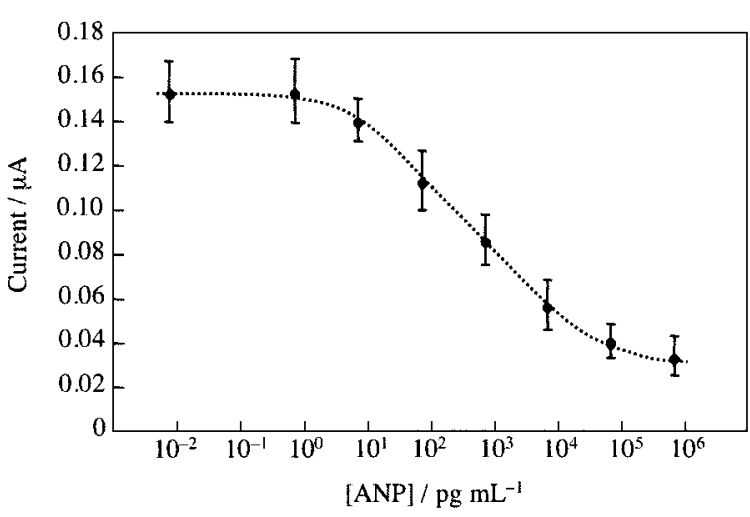

Fig. 5 Calibration curve for ANP in the buffer solution using DIbased enzymatic electrode (mean $\pm \mathrm{SD}$ ). The assay procedure and conditions were described in the text. The detection of PAP was conducted in a buffer solution $(600 \mu \mathrm{L}, \mathrm{pH} 7.4)$ containing $40 \mathrm{U}$ DI and $1 \mathrm{mM}$ NADPH.

(data not shown). The immobilization of DI was carried out with a BSA-conjugated method. ${ }^{30}$ The modified electrode also gave a bioelectrocatalytic voltammogram of PAP. A 200-fold enhanced anodic current for PAP was obtained by adding NADPH to the PAP test solution. Since the amplification magnitude in the system in which DI was present in solution was already about 100-fold greater (Fig. 2), the effect of enzyme immobilization (concentration on the electrode surface) was much less in the case of DI compared with the case of GOD (Table 1). The detection limit was slightly lowered from $4 \mathrm{nM}$ to $1 \mathrm{nM}$ by immobilizing DI (Fig. 4b). These results also seem to support the above discussion. Since the diffusion of GOD is slower than that of DI, a larger immobilization (concentration) effect should be observed. Some instability and loss of activity of DI in the film may also be postulated to explain these results. The electrochemical response of PAP with the DI-immobilized electrode decayed to less than half within two days at room temperature, indicating that DI was not very stable within the present film.

\section{ANP measurement}

The above enzymatic recycling electrode was combined with an enzyme immunoassay method for ANP determination (Fig. 1). Under optimum conditions, the calibration curve of this DI (in solution)-based immunosensor for ANP using amperometric detection was constructed as shown in Fig. 5, where the obtained steady currents were plotted against the concentrations of ANP in the sample solutions. Although the current remained almost unchanged when the ANP concentration was lower than $5 \mathrm{pg}$ $\mathrm{mL}^{-1}$, it decreased with increasing ANP concentration when the ANP concentration was higher than $10 \mathrm{pg} \mathrm{mL}^{-1}$. An increase in 
Table 2 Comparison of the current values obtained for various concentrations of ANP spiked into serum and a buffer ${ }^{\mathrm{a}}$

\begin{tabular}{lcccr}
\hline $\begin{array}{l}\text { Run } \\
\text { No. }\end{array}$ & $\begin{array}{c}\text { ANP } \\
\text { added } \\
\text { value }\end{array}$ & $\begin{array}{c}\text { Serum } \\
\text { measurement/ } \\
\mathrm{nA}\end{array}$ & $\begin{array}{c}\text { Calibration curve } \\
\text { from Fig. 5/ } \\
\mathrm{nA}\end{array}$ & $\begin{array}{c}\text { Ratio, } \\
\%\end{array}$ \\
\hline 1 & $0 \mathrm{pg} \mathrm{mL}^{-1}$ & 144 & 150 & 96 \\
2 & $10 \mathrm{pg} \mathrm{mL}^{-1}$ & 139 & 137 & 101 \\
3 & $100 \mathrm{pg} \mathrm{mL}^{-1}$ & 116 & 110 & 105 \\
4 & $1 \mathrm{ng} \mathrm{mL}^{-1}$ & 76 & 81 & 94 \\
5 & $10 \mathrm{ng} \mathrm{mL}^{-1}$ & 45 & 53 & 85 \\
\hline
\end{tabular}

a. The current values in the buffer solutions were estimated from the calibration curve in Fig. 5.

ANP within the sample caused a decrease in unreacted ALP-Ab, and thus a decrease in ALP activity on the ANP-attached gold substrate. Hence, the electrode response of PAP decreased in proportion to an increase in the ANP concentration. A dynamic range from $10 \mathrm{pg} \mathrm{mL}^{-1}$ and $100 \mathrm{ng} \mathrm{mL}^{-1}$ was obtained in the present system. This indicates that our immunosensor is sufficient for monitoring the ANP concentration in patients' blood samples, since the blood levels are reported to range from about $40 \mathrm{pg} \mathrm{mL}^{-1}$ and $1 \mathrm{ng} \mathrm{mL}^{-1}$, and the sensitivity is equivalent to photometric assay methods. The relative standard deviation (RSD) for nine replicated measurements of a $10 \mathrm{pg} \mathrm{mL}^{-1} \mathrm{ANP}$ $100 \mathrm{pg} \mathrm{mL}^{-1} \mathrm{ANP}, 1 \mathrm{ng} \mathrm{mL}^{-1} \mathrm{ANP}$, and $10 \mathrm{ng} \mathrm{mL}^{-1}$ ANP were 8, 12,13 , and $21 \%$, respectively. These values would be improved by decreasing the concentration of the ALP labeled antibody, which could lead to increase the sensitivity, although the dynamic range would be smaller. ${ }^{31}$ However, we consider that the present RSD values would be acceptable for on-site monitoring of natriuretic peptide for clinical diagnosis, because the peptide concentration in blood significantly increases in heart failure patients. ${ }^{11,12}$

\section{Recovery tests of spiked samples with ANP}

To explore the applications of the present method, we performed recovery tests for ANP spiked in human serum. The human serum was a 1:5 diluted sample that was filtered before the measurement. Table 2 compares the current values obtained for various concentrations of ANP spiked into human serum with those spiked into a buffer solution. The recovery was in the range of $85-105 \%$. After considering the experimental error, we conclude that satisfactory recovery test values were realized over a wide concentration range of $10 \mathrm{pg} \mathrm{mL}^{-1}$ to $1 \mathrm{ng}$ $\mathrm{mL}^{-1}$. When an unfiltered serum sample solution was used, we could not obtain good agreement between the ANP spiked into the serum and the ANP spiked into the buffer. The observed current value for ANP in unfiltered serum was decreased by almost $50 \%$ as compared with that for ANP in the buffer solution. This suggests that large molecules in the serum sample adsorbed non-specifically onto the ANP-immobilized surface (B/F separation substrate), and blocked the specific binding of the free form of antibody, which could lead to the decrease in the observed current.

\section{Conclusions}

We compared the capabilities of several redox enzymes to function in an enzymatic recycling electrode system for PAP, and found that DI was the best enzyme for the amplification of the electrochemical signal of PAP. A highly-sensitive electrochemical enzyme immunoassay system based on PAP recycling was developed to measure low concentrations (ppt level) of the analytes. The present system could detect ANP in human serum with satisfactory sensitivity. Although the total time for one assay required $80 \mathrm{~min}$, this can be reduced by applying the present method to a microfluidics system, and this study is now in progress.

\section{Acknowledgements}

This work was supported financially by the New Energy and Industrial Technology Development Organization (NEDO) of Japan.

\section{References}

1. K. Nakao, Y. Ogawa, S. Suga, and H. Imura, J. Hypertens., 1992, 10, 907.

2. J. S. Floras, Circulation, 1990, 81, 1860.

3. Y. Saito, K. Nakao, K. Nishimura, A. Sugawara, K. Okumura, K. Obata, R. Sonoda, T. Ban, H. Yasue, and H. Imura, Circulation, 1987, 76, 115.

4. S. S. Gottlieb, M. L. Kukin, D. Ahern, and M. Packer, J. Am. Coll. Cardiol., 1989, 13, 1534.

5. H. Yasue, M. Yoshimura, H. Shimada, K. Kurita, K. Kugiyama, M. Jougasaki, H. Ogawa, K. Okumura, K. Mukoyama, and K. Nakao, Circulation, 1994, 90, 195.

6. G. Sagnella, Clin. Sci., 1998, 95, 519.

7. T. A. McDonagh, S. D. Robb, D. R. Murdoch, J. J. Morton, I. Ford, C. E. Morrison, H. Tunstall-Pedoe, J. J. McMurray, and H. J. Dargie, Lancet, 1998, 351, 9.

8. H. Niinuma, M. Nakamura, and K. Hiramori, Cardiology, 1998, 90,89 .

9. R. W. Troughton, C. M. Frampton, T. G. Yandle, E. A. Espiner, M. G. Nicholls, and A. M. Richards, Lancet, 2000, 355, 1126.

10. M. Yoshimura, H. Yasue, and H. Ogawa, Can. J. Physiol. Pharmacol., 2001, 79, 730.

11. Y. Katoh, T. Kurosawa, S. Takeda, S. Kurosawa, H. Sakamoto, F. Marumo, and R. Kikawada, Lancet, 1986, 1, 851.

12. Q. Dao, P. Krishnaswamy, R. Kazanegra, A. Harrison, R. Amirnovin, L. Lenert, P. Clopton, J. Alberto, P. Hlavin, and A. S. Maisel, J. Am. Coll. Cardiol., 2001, 37, 156.

13. M. Kono, A. Yamaguchi, T. Tsuji, A. Misaki, K. Igano, K. Ueki, M. Fujishima, A. Ueda, K. Inoue, K. Nakao, and K. Imura, Jpn. Soc. Nucl. Med. Technol., 1993, 13, 2.

14. A. Clerico, G. Jervasi, M. G. D. Chicca, S. Maffei, S. Berti, L. Sabatino, S. Turchi, F. Cazzuoal, C. Manfredi, and A. Biagini, Clin. Chem., 1996, 42, 1627.

15. A. Clerico, S. D. Ry, and D. Giannessi, Clin. Chem., 2000, $46,1529$.

16. A. Clerico and M. Emdin, Clin. Chem., 2004, 50, 33.

17. H. Matsuura, Y. Sato, O. Niwa, and F. Mizutani, Anal. Chem., 2005, 77, 4235.

18. F. Scheller, C. Bauer, A. Makower, U. Wollenberger, A. Warsinke, and F. Bier, Anal. Lett., 2001, 34, 1233.

19. L. Stoica, A. L.-Sjölander, T. Ruzgas, and L. Gorton, Anal. Chem., 2004, 76, 4690.

20. F. Mizutani, S. Yabuki, and M. Asai, Biosens. Bioelectron., 1991, 6, 305.

21. J. Zhang and A. Cass, Anal. Chim. Acta, 2000, 408, 241.

22. Y. Mie, D. Kato, O. Niwa, and F. Mizutani, 
Electrochemistry, 2006, 174, 138.

23. B. Huang, H. Wu, S. Kim, and R. N. Zare, Lab Chip, 2005, $5,1005$.

24. O. Niwa, Y. Xu, H. Halsall, and W. Heineman, Anal. Chem., 1993, 65, 1559.

25. K. Kano and T. Ikeda, Anal. Sci., 2000, 16, 1013.

26. Y. Ogino, K. Takagi, K. Kano, and T. Ikeda, J. Electroanal. Chem., 1995, 396, 517.

27. M. T. Stankovich, L. M. Schopfer, and V. Massey, J. Biol. Chem., 1978, 253, 4971.
28. S. Ito, S. Yamazaki, K. Kano, and T. Ikeda, Anal. Chim. Acta, 2000, 424, 57.

29. Y. Okahata, T. Tsuruta, K. Ijiro, and K. Ariga, Thin Solid Films, 1989, 180, 65.

30. D. Kato, S. Iijima, R. Kurita, Y. Sato, J. Jia, S. Yabuki, F. Mizutani, and O. Niwa, Biosens. Bioelectron., 2007, 22, 1527.

31. R. Kurita, Y. Yokota, Y. Sato, F. Mizutani, and O. Niwa, Anal. Chem., 2006, 78, 5525. 